\section{Índice de desenvolvimento da família: uma análise comparativa em 21 municípios do Estado do Rio de Janeiro, Brasil}

\author{
Family development index: a comparative analysis \\ in 21 municipalities in Rio de Janeiro State, Brazil
}

\begin{abstract}
This article presents an adaptation of the family development index, with a detailed description of the results of its application in 21 municipalities in the State of Rio de Janeiro, Brazil, in 2000. The research is part of the Baseline Study on the Project for Expansion and Consolidation of the Family Health Strategy and was proposed as an instrument for monitoring and analyzing the municipal reality in the context of a family-centered public policy. The results show a serious-tosevere situation for families in the State of Rio de Janeiro. The most critical dimensions relate to inequalities in results, availability of resources, and labor market access, in addition to a key aspect involving inequality of opportunities, namely access to knowledge. The most vulnerable groups consist of families headed by individuals over 65 years of age and families headed by women.
\end{abstract}

Social Inequity; Family; Family Health Program
Alberto Lopes Najar 1

Tatiana Wargas de Faria Baptista 1

Carla Lourenço Tavares de Andrade 1

\section{Introdução}

O ano de 2005 foi o início dos Estudos de Linhas de Base definidos pelo Ministério da Saúde para os municípios brasileiros com 100 mil habitantes ou mais, envolvidos no Projeto de Consolidação e Expansão do Saúde da Família nos grandes centros urbanos (PROESF). Esses estudos almejavam a constituição de uma proposta de monitoramento e de avaliação do Programa Saúde da Família (PSF), somando esforços a outras estratégias do Ministério da Saúde para acompanhamento do programa 1,2,3.

A construção de uma linha de base configurava alguns desafios, o maior deles: a definição de uma metodologia que pudesse expressar a diversidade das situações encontradas nos municípios, seja no âmbito gerencial e/ou assistencial, seja no das necessidades de saúde. Muitas questões suscitavam o debate: que aspectos priorizar na constituição de uma linha de base dos municípios? Que indicadores poderiam expressar a situação social e de saúde da população? Que indicadores poderiam traduzir a situação das famílias nos territórios? Que famílias eram essas e que dificuldades encontravam?

O trabalho de identificação de fontes de informação para atender a essas questões evidenciou um vazio de reflexão sobre a questão das famílias, pois, se de um lado, havia informação disponível sobre o adoecer e morrer da população, de outro, não havia qualquer dado sobre as famílias de que 
se falava (configuração, principais problemas). Noutro aspecto, o modelo de família que emergia do texto oficial parecia se contrapor a uma realidade de demandas básicas e simples, que nunca eram atendidas. Como evidenciar a discrepância entre a situação oficial e a situação real?

Este estudo surge no contexto dessa discussão com o objetivo de constituir informações acerca das diferentes famílias que convivem no cenário brasileiro, possibilitando a identificação de grupos sociais mais vulneráveis e gerando subsídios para a definição de políticas que atendam a estes grupos e garantam maior eqüidade em saúde. Entende-se por vulnerabilidade um conjunto de aspectos que vão além do individual, abrangendo elementos coletivos, contextuais, que levam à suscetibilidade a doenças ou agravos, e que têm em conta aspectos que dizem respeito à disponibilidade ou a carência de recursos destinados à proteção das pessoas 4 .

O estudo é uma adaptação do índice de desenvolvimento da família (IDF), desenvolvido por Carvalho et al. 5, e detalha os resultados de sua aplicação em 21 municípios do Estado do Rio de Janeiro, Brasil no ano 2000. O que se apresenta aqui é o resultado de uma escolha, é uma tentativa de retratar, usando-se uma metodologia preexistente, a situação das famílias em seu aspecto mais geral, assinalando, em largos traços, as condições que podem ser aferidas para a população da cidade como um todo, e que deveriam ser impactadas pelas condições de saúde prevalentes. Consideraram-se na análise das famílias a situação de vulnerabilidade, o acesso ao trabalho, a disponibilidade de recursos, as condições do desenvolvimento infanto-juvenil e as condições habitacionais, identificadas segundo grupos mais sensíveis, tais como: mulheres que são chefes de domicílio, crianças, idosos e chefes de família não-brancos. O que se pretende é formar a base de uma escolha mais consistente, que não faça pressupostos sobre como as famílias se organizam, mas que as considere apenas como coalizões complexas que envolvem elementos cujo universo de possibilidades, no qual a própria família também é uma variável e, não, uma constante, é muito vasto.

\section{As dimensões sócio-espaciais da pobreza e o Programa Saúde da Família}

A relação entre condições sociais e saúde não é recente. Vários estudos indicam que o estado de saúde das pessoas é fortemente associado às condições sociais dos indivíduos ${ }^{6}$. Uma evidência dos componentes sociais no estado de saúde pode ser observada no fato de que algu- mas doenças desapareceram, outras surgiram e mesmo reapareceram, porém as desigualdades sociais nos processos de adoecimento e morte são constantes 7,8 .

Alguns estudos sugerem um tratamento para a questão com base no ciclo de vida ${ }^{9}$. Dessa forma, diferenças na saúde de adultos poderiam ser explicadas por uma trama de fatores biológicos e sociais atuando ao longo de suas vidas 10. Há ainda um número crescente de estudos que busca associar características das áreas onde as pessoas vivem com a saúde, com objetivo de aprimorar o entendimento das desvantagens na saúde experimentadas por determinados grupos sociais 11. As relações entre ambiente, condição social e saúde representam um eixo importante no entendimento da mobilidade social e da manutenção das desigualdades sociais 12 .

A pobreza urbana não se distribui de forma homogênea e uniforme no espaço intra-urbano, da mesma forma que também não se concentra em alguma área contígua definida, ou seja, a segregação social no espaço não é "perfeita". Nem todos os assentamentos identificados como de baixa renda são ocupados apenas por pobres e nem todos os pobres ocupam áreas tidas como carentes. Essa constatação imediata para qualquer observador da metrópole reflete, ao mesmo tempo, algumas das dificuldades clássicas para se definir, caracterizar e localizar a pobreza urbana e questões não triviais no nível da formulação de políticas públicas compensatórias.

Não é necessária longa incursão na literatura para se dar conta das formidáveis dificuldades de ordem conceitual, analíticas e metodológicas envolvidas em qualquer tentativa de definição, caracterização e identificação da chamada pobreza urbana, bem como dos efeitos, na estrutura social, da subsunção de diversas porções do território às dinâmicas do capital financeiro, havendo razoável consenso, entre os estudiosos do tema, da precariedade dos indicadores disponíveis. Tem-se presente aqui a já considerável literatura que anima esse debate 13,14,15,16.

Deve a pobreza urbana ser medida por meio da renda familiar ou individual? Em termos absolutos ou relativos? Ou, talvez, segundo uma cesta de consumo sujeita aos caprichos das diferenças culturais e/ou regionais? Ou ainda, de modo mais particular, com base nos requisitos de consumo calórico ou protéico para a sobrevivência, ou por meio de um indicador genérico de adequação energética? Ou, alternativamente, pode-se pensar em níveis preestabelecidos para necessidades básicas não atendidas de saúde, de educação, de saneamento etc., cuja composição num único indicador também envolve certa arbitrariedade na ponderação e na própria mensuração ${ }^{17}$. Não se 
devem ignorar tampouco os problemas associados à variação temporal no poder aquisitivo do salário mínimo, da mesma forma que os problemas relacionados à qualificação dos grupos populacionais, quando se levam em consideração o sexo e a cor. Essas considerações caracterizam a pobreza, antes de tudo, como uma síndrome multidimensional de carências diversas - de saúde, de educação, de habitação, de saneamento, de lazer, de nutrição etc. Essas ambigüidades, entretanto, implicam dificuldades práticas evidentes, como, por exemplo, delimitar no tempo e no espaço a população-alvo de alguma política setorial ou regional específica, isto porque essas carências não incidem cumulativamente sobre os mesmos grupos populacionais, conforme evidenciado na discussão sobre os métodos de medição da pobreza, seja através de linha de pobreza, seja por meio das necessidades básicas não satisfeitas. Alguns resultados empíricos ilustram bem o problema apontado:

- A linha de pobreza medida através do salário mínimo varia significativamente, sugerindo que ele não reflete as diferentes condições ou custo de vida vigentes 18,19;

- Constatam-se o agravamento da pobreza nos anos de crise e a significativa redução na proporção de pobres em períodos de expansão da atividade econômica, indicando que a pobreza urbana depende da conjuntura econômica 20 ;

- A renda não reflete adequadamente aspectos não-monetários da condição de vida 21 ;

- Estudos sugerem que não se pode supor a correspondência entre suficiência alimentar e poder aquisitivo, pois famílias com alto poder aquisitivo podem ser identificadas com baixa taxa de adequação energética, ao mesmo tempo em que não são necessariamente as famílias que menos gastam as mais mal-alimentadas 22,23;

- Mesmo no caso de populações indiscutivelmente carentes há um descolamento entre os atributos sócio-econômicos, seja em termos de poder aquisitivo, seja em termos do acesso efetivos a bens e serviços, podendo apresentar níveis de poder aquisitivo compatíveis com aqueles de melhor situação sócio-econômica 24 ;

- Famílias de baixo poder aquisitivo parecem realizar trade offs entre as diversas manifestações de carências 25 ;

- Pesquisas constataram que moradores de assentamentos tomados como ícones da "marginalidade urbana" não se encontravam necessariamente ocupados em atividades informais ou irregulares 18,26;

- Diversos estudos identificaram a grande variedade e a diversidade de modalidades de habitação e inserção social da população de baixa renda $27,28,29,30$.
As questões apontadas, menos do que minimizarem ou mesmo relativizarem as manifestações da pobreza, indicam a enorme complexidade do fenômeno. Ao se considerarem como população alvo de programas e/ou políticas públicas todos os que enfrentam algum constrangimento na situação de, pelo menos, um tipo de carência - no consumo individual, familiar ou coletivo -, atingir-se-ia mais da metade da população brasileira. Se, no lugar de considerar o conjunto definido com base na união de todos os subconjuntos de população com alguma carência, se optasse pelo atendimento prioritário daqueles identificados como pertencentes à interseção de todas estas carências, isto é, os mais necessitados, o problema não seria menos complicado, sendo remetido, por definição, tanto à constituição de um "pacote" de medidas, quanto à localização e delimitação geográfica desta mesma população, ou à definição de critérios de acesso que permitisse particularizar o grupo alvo.

Quanto à primeira dificuldade, sabe-se que, se por um lado, muitas carências tendem a reforçar-se mutuamente, por outro, dificuldades na tarefa de estabelecimento do mix de intervenção sobre cada item e para a comunidade acarretariam desperdícios não negligenciáveis. Mesmo que certos segmentos populacionais sejam facilmente identificáveis, dificuldades têm demonstrado, na prática, que políticas voltadas especificamente para essas áreas tendem a apresentar resultados bastante duvidosos ou questionáveis, tanto no controle dos inevitáveis vazamentos num contexto de óbvia porosidade com relação às comunidades vizinhas, implicando ambigüidade de definição das fronteiras físicas, quanto na concepção de meios eficazes de reverter a situação de forma auto-sustentável. Ou seja, a discriminação de grupos/população alvo num contexto não-espacializado encerra, portanto, grandes problemas originários do fato de que este grupo nem sempre, ou dificilmente, é constituído de desempregados, com baixo nível de educação e qualificação, desnutridos etc.

Esta discussão é de extrema importância no debate do PSF, em especial se tratando da expansão desta política para os grandes centros urbanos. O PSF instituído como uma política nacional em 1994, surgiu com o objetivo principal de atender prioritariamente as áreas de maior risco social, inicialmente a população residente nas localidades delimitadas no Mapa da Fome do Instituto de Pesquisa Econômica e Aplicada, e posteriormente, os municípios inseridos no Programa Comunidade Solidária ou no Programa de Redução da Mortalidade Infantil 31. A inflexão da política se efetivou a partir de 1996 quando o Ministério da Saúde editou uma nova norma 
orientadora para o SUS e instituiu o Piso da Atenção Básica, tendo como um dos componentes de incentivos do piso o PSF. O Programa assumiu um caráter mais abrangente e se constituiu numa estratégia de reorientação do modelo assistencial 32,33.

Desde 2003 o Ministério da Saúde busca requalificar a Estratégia Saúde da Família e inserila no debate de construção de uma política nacional de reestruturação da atenção básica. No ano de 2006, o Ministério da Saúde editou o documento Política Nacional da Atenção Básica 34 no qual reafirmou o PSF como estratégia de reorientação do modelo assistencial pautado nos princípios da universalidade e integralidade. $\mathrm{O}$ PROESF insere-se nesse contexto num esforço de expansão da política nos grandes centros urbanos, mas o que se verificou nos últimos anos, especialmente nesses municípios, foi a tendência de priorização da implantação do PSF nas áreas consideradas mais pobres, como uma estratégia focalizada de expansão de cuidados básicos de saúde, voltada a grupos populacionais sob maior risco social e expostos a precárias condições sanitárias 35 . Fato é que a implantação da política nos grandes centros trouxe à tona a situação de desigualdade e a necessidade de enfrentamento dos problemas de forma diferenciada do que vinha sendo realizado nos demais municípios. Enfrentar a discussão da desigualdade social e das condições sócio-espaciais da pobreza pode contribuir na orientação de políticas e na definição das estratégias a serem adotadas em cada âmbito, sem que isto implique a construção de políticas pobres para pobres, mais do que isto, possibilita uma compreensão mais abrangente do fenômeno da pobreza sem restringi-la a espaços delimitados ou padrões já superados de identificação destes grupos.

\section{Metodologia}

A metodologia proposta neste estudo visa a subsidiar a discussão sobre a definição de indicadores de monitoramento e avaliação no âmbito do PROESF, colocando como eixo central do debate a família. O estudo insere-se na pesquisa de linha de base do PROESF lote Sudeste II, que corresponde ao Estado do Rio de Janeiro e compreende 22 municípios com mais de 100 mil habitantes.

O estudo de caráter ecológico visa a abordar a situação da família brasileira e a traçar um quadro de possíveis vulnerabilidades, de acordo com o estágio de desenvolvimento das famílias. Assume-se que há uma carência de estudos dessa natureza e que há uma necessidade fundamental de discussão para a crítica e desenvolvimento de uma política pública que tomou a família como objeto.

A metodologia consiste numa adaptação do IDF desenvolvido por Carvalho et al. 5. O objetivo principal desse índice é a construção de um indicador que sintetize as dimensões relevantes da pobreza no nível de cada família, com a possibilidade de agregação para qualquer grupo demográfico, tais como as famílias chefiadas por mulheres, idosos, negros ou qualquer outro grupo que se especifique. Assim, mesmo que o IDF não expresse exatamente a configuração das famílias no Brasil contemporâneo, pode contribuir para uma reflexão mais específica sobre esta questão e agregar valor na configuração de propostas políticas. O uso dessa metodologia visou à identificação de vulnerabilidades, não necessariamente entre os pobres, mas nas diferentes famílias, somando elementos para a análise das políticas públicas e para a configuração de estratégias de enfrentamentos das necessidades de saúde, compreendidas de forma abrangente.

O IDF adaptado ao propósito deste estudo utilizou os dados do Censo Demográfico 200036 no lugar da Pesquisa Nacional por Amostra de Domicílios (PNAD), já que a PNAD não possibilita a utilização do dado no nível municipal. Conforme o Censo Demográfico 2000 36, "família” é um conjunto de pessoas que co-habitam um mesmo espaço, seguindo "normas de convivência" e regras estabelecidas, enquanto o domicílio é a estrutura física. Essa diferenciação parece-nos fundamental para a discussão sobre família, já que podem conviver uma ou mais famílias num mesmo domicílio. Nesse sentido, a opção pela utilização dos dados do Censo permitiu uma diferenciação das famílias no interior dos domicílios.

Há que se ressaltar que tanto as informações produzidas pelas PNADs como pelo Censo Demográfico possuem grandes limitações para o uso na produção de indicadores. No caso específico do Censo Demográfico, o fato de serem coletados decenalmente geram ciclos muito longos para um monitoramento, além disto há um conjunto restrito de variáveis disponíveis e adequadas ao objetivo do IDF, o que também dificulta a construção do índice e o restringe a um grupo limitado de opções. Mesmo assim, buscamos utilizar o Censo Demográfico com o objetivo de exercitar o olhar do dado no âmbito municipal, o que não nos permite a PNAD. Outras opções podem ser exercitadas, como o cadastro único, tal como indicam os idealizadores do IDF 5 . Ainda assim essa é uma metodologia que exige aperfeiçoamentos e o objetivo deste trabalho foi testar possibilidades de uso, mais do que a construção de um indicador finalizado. 
O IDF original é constituído por seis dimensões, 26 componentes e 48 indicadores. No IDF adaptado mantiveram-se as seis dimensões propostas, com pequenos ajustes na conceituação das mesmas. Reduziu-se para 22 o número de componentes e ampliaram-se para 53 os indicadores. Para se obter o indicador sintético adotou-se um sistema neutro de pesos, tal como o utilizado para construir o Índice de Desenvolvimento Humano (IDH). A escolha dos indicadores que compõem o índice sintético foi feita com base em perguntas disponíveis do Censo e da compreensão dos autores do peso e importância de cada pergunta. Foram realizadas rodadas de discussão com toda a equipe para a definição das perguntas a serem consideradas, o que é compatível com a orientação da metodologia original que assume ser esta uma opção da sociedade e não uma questão técnica ou estatística.

As seis dimensões das condições de vida, avaliadas baseando-se nas informações do Censo e sintetizadas no IDF, foram: (a) ausência de vulnerabilidade; (b) acesso ao conhecimento; (c) acesso ao trabalho; (d) disponibilidade de recursos; (e) desenvolvimento infanto-juvenil; (f) condições habitacionais.

As dimensões visam a compreender um conjunto de necessidades básicas das famílias e permitem expressar as desigualdades entre grupos de famílias. Para cada dimensão foram identificados componentes e diferentes indicadores que os representam, conforme a Tabela 1. É exatamente nessa parte da metodologia que a adaptação do índice foi mais incisiva, com o objetivo de atender às questões que norteavam o estudo, e também se adequar à mudança da base de informações da PNAD para o Censo Demográfico.

Em cada uma das dimensões e componentes foram feitas escolhas que visavam a precisar a situação das famílias nas diferentes dimensões; por trás das escolhas alguns pressupostos e concepções teóricas embasados na compreensão e estudo da realidade social brasileira.

Para o processamento das informações e composição do índice foi preservada a idéia original de perguntas feitas às famílias. Cada indicador expressa uma pergunta, foram 53 perguntas às famílias com as respostas codificadas no formato "sim" ou "não". Cada "sim" foi computado positivamente, aumentando a pontuação na direção de um índice de desenvolvimento maior. Dessa forma, o IDF pode variar entre zero (para as famílias em pior situação) e um (para as que se encontram em melhor situação), segundo as escolhas feitas. Quanto maior o índice, maior o desenvolvimento do município/região.

A segunda fase da construção do índice foi a da definição de pesos para todas as variáveis.
O indicador sintético de cada um dos 22 componentes é a média aritmética das variáveis utilizadas para representar cada componente de cada dimensão. Analogamente, a construção do indicador sintético de cada dimensão é a média aritmética de seus respectivos componentes. $\mathrm{O}$ IDF é, então, calculado como a média aritmética dos indicadores sintéticos das seis dimensões que o compõem.

A matriz de dimensões, componentes e indicadores apresentados é resultado de uma escolha que, como toda escolha, influencia os resultados e as análises subseqüentes.

Foram considerados como pontos de corte para a análise do índice $1 / 2(0,50)$ e 2/3 $(0,67)$, indicativos de situações muito graves e graves, respectivamente, no que se refere ao desenvolvimento das famílias. Da mesma forma, escolheram-se quatro grupos que os estudos de corte sociológico apontam como predominantemente vulneráveis: crianças, terceira idade, mulheres chefes de domicílio e não-brancos chefes de família.

Os resultados, apresentados em seguida, devem ser lidos como um aspecto da linha de base de cada uma das cidades integrantes do estudo. A metodologia foi aplicada em 21 dos 22 municípios do lote Sudeste II, excetuando-se o Município de Mesquita, que teve sua emancipação no ano de 2001, posterior, portanto, ao Censo Demográfico 2000.

Como se trata de um estudo ecológico, as observações e análises aqui realizadas estão referidas a um ano, o que pode apenas possibilitar um retrato dessa realidade, mas não uma comparação ou mesmo qualificação de valor sobre a situação em que se encontram. É importante também atentar para o risco da falácia ecológica: como se trata de informações do conjunto da população nesses municípios, elas não podem ser extrapoladas para casos específicos ou situações particulares.

O IDF é um índice proposto com o objetivo de sintetizar as dimensões relevantes da pobreza e sua expressão nas famílias. Com a sua adaptação neste estudo, visamos a buscar variáveis outras que podem ou não expressar a situação das famílias, mas que nos possibilitam ao menos colocar em questão as diferentes condições enfrentadas pelas famílias, o que também exige maior apuração metodológica e provavelmente novas adaptações. 
Dimensões, componentes e indicadores do índice de desenvolvimento das famílias

Dimensões Componentes Indicadores

1) Ausência de vulnerabilidade - se expressa pelo volume adicional de recursos que uma família precisa dispor para satisfazer suas necessidades básicas

2) Acesso ao conhecimento - verifica que famílias apresentam índices melhores de acordo com o responsável, sendo este um proxy da situação familiar
Atenção e cuidado com crianças, adolescentes e jovens - verifica a presença de um destes grupos na família

Presença do cônjuge - verifica a presença do cônjuge

Ausência de desvantagem física - verifica se a família possui algum membro com desvantagem física

Ausência de desvantagem social - verifica se a família apresenta algum ente com transtorno mental, idoso, ou negro, residência em situação precária ou responsável pela família habitando há menos de 20 anos na cidade

Analfabetismo - todo indivíduo que não sabe ler e escrever. Somou-se a condição mínima de quatro anos de estudo para o responsável pela família como situação de corte para pontuar positivamente o acesso ao conhecimento. Se averiguou a presença de adultos analfabetos na família

Escolaridade - foi utilizado o recurso do indicador em cascata; a cada resposta positiva, somou-se um ponto na dimensão e na condição da família
V1 - ausência de menores de um ano V2 - ausência de criança

V3 - ausência de criança ou adolescente V4 - ausência de criança ou adolescente ou jovem

V5 - responsável pela família é do sexo masculino

V6 - responsável pela família é do sexo masculino e vive em presença do cônjuge

V7 - ausência de pessoa com incapacidade visual na família

V8 - ausência de pessoa com incapacidade auditiva na família

V9 - ausência de pessoa com incapacidade para deambular na família

V10 - ausência de pessoa com deficiências físicas na família

V11 - ausência de pessoa com problemas mentais permanentes na família V12 - ausência de não-brancos na família V13 - família não mora em setor classificado como aglomerado subnormal

V14 - responsável pela família reside na mesma cidade desde 1995

V15 - ausência de adulto com idade igual ou maior do que 75 anos.

C1 - responsável pela família sabe ler e escrever C2 - responsável pela família tem mais do que 4 anos de estudo

C3 - ausência de adulto (pessoa com 25 anos ou mais) analfabeto

C4 - responsável pela família tem pelo menos ensino fundamental completo ou primeiro grau

C5 - responsável pela família tem pelo menos ensino médio ou segundo grau

C6 - responsável pela família com alguma educação superior

C7 - algum outro componente da família com alguma educação superior 
Tabela 1 (continuação)

3) Acesso ao trabalho - compreende a situação do responsável pela família no que tange à inserção no mercado de trabalho e condição de renda para satisfação das necessidades da família
4) Disponibilidade de recursos - identifica as famílias que se encontram abaixo da linha de pobreza. Considerou-se como pobreza, para o caso do Rio de Janeiro, o valor de R\$113,00 per capita, tomando como referência a definição de Haselbalg 37

\section{5) Desenvolvimento infanto-juvenil - agrega} informações sobre as condições das crianças e jovens nas famílias investigadas para uma análise do desenvolvimento da família como um todo
Disponibilidade de trabalho - corresponde à situação de trabalho em que se encontram o responsável e os adultos da família. Identifica se há remuneração pelo trabalho

Qualidade do posto de trabalho - qualifica o posto de trabalho do responsável, considerando como indicador de qualidade a situação de contribuinte da previdência social, o número de horas de trabalho/dia numa semana de 5 dias

Remuneração - utilizou-se o indicador em cascata para somar positivamente a situação do responsável conforme a maior remuneração obtida

Pobreza

Proteção contra o trabalho precoce - identifica se há crianças ou adolescentes na família trabalhando

Acesso à escola - identifica a participação da criança e do adolescente na escola
T1 - responsável pela família trabalha com remuneração

T2 - adultos (25 anos ou mais) trabalham com remuneração

T3 - responsável pela família é contribuinte de previdência oficial

T4 - responsável pela família não trabalha mais do que 10 horas/dia - considerou-se semana de 5 dias de trabalho

T5 - responsável pela família com o total de rendimentos do trabalho principal superior a 1 salário mínimo

T6 - responsável pela família com o total de rendimentos do trabalho principal superior a 2 salários mínimos

T7 - responsável pela família com p total de rendimentos do trabalho principal superior a 3 salários mínimos

R1 - renda familiar per capita superior à linha de pobreza regionalizada
D1 - ausência de crianças entre 10 e 11 anos trabalhando

D2 - ausência de crianças e adolescentes entre 10 e 17 anos trabalhando

D3 - ausência de crianças entre 3 e 6 anos fora da escola

D4 - ausência de criança/adolescente entre 7 e 14 anos fora da escola

D5 - ausência de criança/adolescente entre 7 e 17 anos fora da escola

Progresso escolar - verifica há quanto tempo a criança e o adolescente freqüentam a escola

D6 - criança/adolescente entre 10 e 14 anos tem mais do que 4 anos de estudo

D7 - adolescente entre 15 e 17 anos tem mais do que 4 anos de estudo

Mortalidade de filhos - verifica a mortalidade infantil na família
D8 - nenhuma mulher teve filho nascido morto D9 - total de filhos nascidos vivos que estavam vivos é igual ao total de filhos tidos

(continua) 
Tabela 1 (continuação)

\begin{tabular}{|c|c|c|}
\hline Dimensões & Componentes & Indicadores \\
\hline \multirow{24}{*}{$\begin{array}{l}\text { 6) Condições habitacionais - compreende um } \\
\text { conjunto de informações sobre as condições gerais } \\
\text { de habitação e que invariavelmente expressam a } \\
\text { capacidade e poder de compra das famílias e sua } \\
\text { situação mais geral }\end{array}$} & Propriedade & H1 - domicílio próprio \\
\hline & & H2 - domicílio próprio e terreno próprio \\
\hline & & \\
\hline & Densidade & H3 - até 3 moradores por dormitório \\
\hline & Abrigabilidade & H4 - existência de banheiro \\
\hline & Acesso a serviço de abastecimento d'água & H5 - abastecimento adequado (rede geral \\
\hline & & e pelo menos um cômodo com canalização \\
\hline & & interna) \\
\hline & Acesso a serviço de esgotamento sanitário & $\begin{array}{l}\text { H6 - esgotamento adequado (rede geral ou } \\
\text { fossa séptica) }\end{array}$ \\
\hline & Acesso a serviço de coleta de lixo & H7 - destino do lixo adequado (lixo coletado \\
\hline & & por serviço de limpeza) \\
\hline & Acesso a serviço de energia elétrica & H8 - existência de iluminação elétrica \\
\hline & Acesso a bens duráveis & H9 - existência de rádio \\
\hline & & H10 - existência de rádio e televisão \\
\hline & & H11 - existência de rádio, televisão e geladeira \\
\hline & & ou freezer \\
\hline & & H12 - existência de rádio, televisão, geladeira \\
\hline & & ou freezer e máquina de lavar roupa \\
\hline & & H13 - existência de rádio, televisão, geladeira \\
\hline & & ou freezer, máquina de lavar roupa e linha \\
\hline & & telefônica instalada \\
\hline & & H14 - existência de rádio, televisão, geladeira \\
\hline & & ou freezer, máquina de lavar roupa, linha \\
\hline & & telefônica instalada e microcomputador \\
\hline
\end{tabular}

Fonte: adaptado de Carvalho et al. 5 .

\section{Resultados}

O IDF calculado para os 21 municípios selecionados é mostrado na Tabela 2. Os resultados mostram uma situação grave ou muito grave da situação das famílias em quatro das seis dimensões definidas no IDF. Destacam-se como muito graves ou mais críticas as dimensões "acesso ao trabalho" e "disponibilidade de recursos", por apresentarem um IDF menor que 0,50. A dimensão "acesso ao conhecimento" apresenta-se também no limite da situação muito grave, do ponto de vista social. Pela análise dos componentes e indicadores que integram essas dimensões, confirmam-se os desafios para a consolidação de políticas públicas na área educacional, de emprego e renda. Com base em estudos recentes sobre o assunto 37,38 , pode-se desenhar um modelo causal no qual a dimensão disponibilidade de recursos é a variável dependente e o acesso ao conhecimento e o acesso ao trabalho as variáveis independentes.

Observando essas três dimensões citadas para o estado e seus dois principais municípios, a capital e Niterói, verifica-se que a situação para o todo não é nada animadora para as duas importantes dimensões "acesso ao trabalho" e "disponibilidade de recursos”. A capital e Niterói seguem de perto os escores do estado. Apenas as dimensões "desenvolvimento infanto-juvenil" e “condições habitacionais” apresentam situações aceitáveis.

Destaque-se que sete dos 21 municípios analisados (Belford Roxo, Duque de Caxias, Itaboraí, Magé, Queimados, São João de Meriti e Teresópolis) apresentam valores abaixo da média do estado para todas as dimensões, exceto “condições habitacionais", que, de resto, é uma 
Índice de desenvolvimento das famílias segundo a classificação por dimensões. Estado do Rio de Janeiro, Brasil, 2000.

\begin{tabular}{|c|c|c|c|c|c|c|c|}
\hline Município & Geral & $\begin{array}{c}\text { Ausência de } \\
\text { vulnerabilidade }\end{array}$ & $\begin{array}{c}\text { Acesso ao } \\
\text { conhecimento }\end{array}$ & $\begin{array}{l}\text { Acesso ao } \\
\text { trabalho }\end{array}$ & $\begin{array}{l}\text { Disponibilidade } \\
\text { de recursos }\end{array}$ & $\begin{array}{c}\text { Desenvolvi- } \\
\text { mento } \\
\text { infanto- } \\
\text { juvenil }\end{array}$ & $\begin{array}{c}\text { Condições } \\
\text { habitacionais }\end{array}$ \\
\hline Angra dos Reis & 0,58 & 0,66 & 0,46 & 0,47 & 0,36 & 0,75 & 0,76 \\
\hline Barra Mansa & 0,58 & 0,67 & 0,48 & 0,47 & 0,31 & 0,74 & 0,76 \\
\hline Belford Roxo & 0,55 & 0,64 & 0,45 & 0,44 & 0,27 & 0,73 & 0,76 \\
\hline Cabo Frio & 0,58 & 0,66 & 0,48 & 0,49 & 0,36 & 0,73 & 0,76 \\
\hline Campos dos Goytacazes & 0,56 & 0,67 & 0,45 & 0,44 & 0,27 & 0,74 & 0,76 \\
\hline Duque de Caxias & 0,57 & 0,64 & 0,46 & 0,46 & 0,32 & 0,73 & 0,76 \\
\hline Itaboraí & 0,55 & 0,64 & 0,42 & 0,44 & 0,29 & 0,72 & 0,76 \\
\hline Macaé & 0,61 & 0,66 & 0,51 & 0,55 & 0,44 & 0,77 & 0,76 \\
\hline Magé & 0,55 & 0,63 & 0,44 & 0,43 & 0,28 & 0,71 & 0,75 \\
\hline Nilópolis & 0,60 & 0,64 & 0,55 & 0,46 & 0,40 & 0,77 & 0,76 \\
\hline Niterói & 0,67 & 0,66 & 0,66 & 0,53 & 0,61 & 0,82 & 0,76 \\
\hline Nova Friburgo & 0,60 & 0,69 & 0,48 & 0,52 & 0,42 & 0,77 & 0,76 \\
\hline Nova Iguaçu & 0,57 & 0,65 & 0,48 & 0,47 & 0,33 & 0,74 & 0,76 \\
\hline Petrópolis & 0,60 & 0,68 & 0,48 & 0,51 & 0,43 & 0,76 & 0,76 \\
\hline Queimados & 0,55 & 0,64 & 0,44 & 0,45 & 0,28 & 0,71 & 0,76 \\
\hline Resende & 0,61 & 0,67 & 0,52 & 0,54 & 0,41 & 0,74 & 0,76 \\
\hline Rio de Janeiro & 0,63 & 0,65 & 0,59 & 0,50 & 0,53 & 0,79 & 0,76 \\
\hline São Gonçalo & 0,59 & 0,66 & 0,50 & 0,48 & 0,37 & 0,78 & 0,76 \\
\hline São João de Meriti & 0,57 & 0,64 & 0,49 & 0,47 & 0,34 & 0,74 & 0,76 \\
\hline Teresópolis & 0,57 & 0,64 & 0,49 & 0,47 & 0,34 & 0,74 & 0,76 \\
\hline Volta Redonda & 0,60 & 0,66 & 0,54 & 0,46 & 0,40 & 0,76 & 0,77 \\
\hline Estado do Rio de Janeiro & 0,60 & 0,65 & 0,52 & 0,48 & 0,42 & 0,77 & 0,74 \\
\hline
\end{tabular}

Fonte: Dados trabalhados com base Censo Demográfico 200036.

dimensão em que todos se apresentam com bons escores.

Nas Tabelas 3 e 4 apresentam-se o IDF, segundo os municípios e os grupos vulneráveis.

Destaca-se o grupo da terceira idade com a pior média estadual, o que também se expressa nos 21 municípios selecionados. Os índices apresentados nesse grupo indicam uma situação muito grave ou grave na maior parte das cidades. Apenas três (Niterói, Nova Iguaçu e Rio de Janeiro) apresentaram índices superiores ao do estado, mesmo assim mantendo índices que indicam uma situação grave. Nesse grupo, as dimensões que pesam mais negativamente são: acesso ao trabalho, acesso ao conhecimento e disponibilidade de recursos. Nas duas últimas dimensões, era um resultado esperado. O padrão de escolaridade exigido há vinte ou trinta anos era diferente do atual, o que faz com que pequena parcela de idosos apresente uma escolaridade de nível superior. Além disso, os rendimentos dos idosos têm servido em muitas famílias como o principal recurso para a sustentação do grupo. Esse é um aspecto importante a se considerar na configuração de políticas públicas, pois, se o idoso, por um lado, traz maior vulnerabilidade para as famílias porque exige mais cuidado/atenção e consome, na grande maioria das vezes, medicamentos e serviços, despendendo mais recursos, por outro, é ele, como apresenta a análise do IDF para este grupo, que mantém ou contribui muito significativamente na sustentação de famílias, o que, de certo modo, tem retirado do idoso a possibilidade de usufruir seus recursos para atender às suas necessidades básicas. Já o baixo índice encontrado na dimensão "acesso ao trabalho" se explica por uma questão metodológica do estudo, à proporção que as variáveis selecionadas com base no Censo não foram sensíveis para captar a situação de aposentadoria e pensão dos idosos.

No grupo de mulheres chefes de domicílio, a situação dos 21 municípios selecionados do estado é igualmente grave. Apenas cinco apresentam um IDF acima do índice estadual (Niterói, 
Índice de desenvolvimento das famílias segundo grupos vulneráveis. Estado do Rio de Janeiro, Brasil, 2000.

\begin{tabular}{|c|c|c|c|c|c|}
\hline Município & Geral & Crianças & $\begin{array}{l}\text { Terceira } \\
\text { idade }\end{array}$ & $\begin{array}{l}\text { Mulheres chefes } \\
\text { de família }\end{array}$ & $\begin{array}{c}\text { Não-brancos chefes } \\
\text { de família }\end{array}$ \\
\hline Angra dos Reis & 0,58 & 0,56 & 0,49 & 0,51 & 0,55 \\
\hline Barra Mansa & 0,58 & 0,58 & 0,48 & 0,50 & 0,54 \\
\hline Belford Roxo & 0,55 & 0,55 & 0,46 & 0,48 & 0,54 \\
\hline Cabo Frio & 0,58 & 0,55 & 0,50 & 0,52 & 0,55 \\
\hline Campos dos Goytacazes & 0,56 & 0,57 & 0,48 & 0,50 & 0,53 \\
\hline Duque de Caxias & 0,57 & 0,56 & 0,47 & 0,50 & 0,55 \\
\hline Itaboraí & 0,55 & 0,54 & 0,47 & 0,49 & 0,54 \\
\hline Macaé & 0,61 & 0,58 & 0,50 & 0,54 & 0,56 \\
\hline Magé & 0,55 & 0,55 & 0,46 & 0,48 & 0,54 \\
\hline Nilópolis & 0,60 & 0,60 & 0,50 & 0,53 & 0,57 \\
\hline Niterói & 0,67 & 0,64 & 0,58 & 0,61 & 0,58 \\
\hline Nova Friburgo & 0,60 & 0,59 & 0,47 & 0,51 & 0,56 \\
\hline Nova Iguaçu & 0,57 & 0,56 & 0,52 & 0,55 & 0,57 \\
\hline Petrópolis & 0,60 & 0,58 & 0,51 & 0,54 & 0,55 \\
\hline Queimados & 0,55 & 0,55 & 0,46 & 0,49 & 0,54 \\
\hline Resende & 0,61 & 0,61 & 0,50 & 0,53 & 0,55 \\
\hline Rio de Janeiro & 0,63 & 0,60 & 0,55 & 0,58 & 0,59 \\
\hline São Gonçalo & 0,59 & 0,59 & 0,49 & 0,53 & 0,57 \\
\hline São João de Meriti & 0,57 & 0,57 & 0,47 & 0,51 & 0,56 \\
\hline Teresópolis & 0,57 & 0,57 & 0,50 & 0,53 & 0,54 \\
\hline Volta Redonda & 0,60 & 0,61 & 0,49 & 0,53 & 0,56 \\
\hline Estado do Rio de Janeiro & 0,60 & 0,58 & 0,51 & 0,54 & 0,56 \\
\hline
\end{tabular}

Fonte: Dados trabalhados com base Censo Demográfico 200036.

Índice de desenvolvimento das famílias segundo as dimensões e os grupos vulneráveis. Estado do Rio de Janeiro, Brasil, 2000

\begin{tabular}{|c|c|c|c|c|c|}
\hline \multirow[t]{2}{*}{ Dimensões } & \multicolumn{5}{|c|}{ Grupos vulneráveis } \\
\hline & Geral & Crianças & $\begin{array}{l}\text { Terceira } \\
\text { idade }\end{array}$ & $\begin{array}{c}\text { Mulheres chefes } \\
\text { de família }\end{array}$ & $\begin{array}{c}\text { Não-brancos chefes } \\
\text { de família }\end{array}$ \\
\hline Geral & 0,60 & 0,58 & 0,51 & 0,54 & 0,56 \\
\hline Ausência de vulnerabilidade & 0,65 & 0,62 & 0,64 & 0,47 & 0,62 \\
\hline Acesso ao conhecimento & 0,52 & 0,53 & 0,43 & 0,51 & 0,46 \\
\hline Acesso ao trabalho & 0,48 & 0,53 & 0,19 & 0,38 & 0,47 \\
\hline Disponibilidade de recursos & 0,42 & 0,20 & 0,42 & 0,42 & 0,32 \\
\hline Desenvolvimento infanto-juvenil & 0,77 & 0,81 & 0,65 & 0,72 & 0,73 \\
\hline Condições habitacionais & 0,74 & 0,74 & 0,74 & 0,74 & 0,74 \\
\hline
\end{tabular}

Fonte: Dados trabalhados com base Censo Demográfico 200036. 
Rio de Janeiro, Macaé, Nova Iguaçu e Petrópolis - Tabela 2). Nesses municípios, com exceção de Nova Iguaçu, estão os melhores índices nas dimensões: disponibilidade de recursos e acesso ao trabalho (Tabela 2), o que pode indicar que é a situação de renda e o acesso ao trabalho (inserção e qualidade do posto) que pesam positiva ou negativamente na situação das famílias que são chefiadas por mulheres. Nesse grupo, quatro dimensões são críticas: acesso ao trabalho, disponibilidade de recursos, ausências de vulnerabilidade e acesso ao conhecimento. Ou seja, as mulheres que chefiam famílias têm encontrado dificuldades para obter trabalho remunerado com carteira assinada, possuem uma renda familiar baixa, apresentam baixa escolaridade e sustentam famílias com crianças, idosos ou pessoas que necessitam de cuidados especiais. Esse é um dos grupos familiares com pior IDF nos municípios. Ou seja, o IDF nesse grupo serve como um alerta para os governantes. As mulheres necessitam de melhor condição de trabalho, salários melhores e certamente mais possibilidade de formação/educação.

Nas famílias com crianças, a situação mais crítica está expressa na dimensão disponibilidade de recursos, com o índice de 0,20. Tal situação revela uma precariedade de renda alarmante neste grupo familiar, servindo como um sinal de alerta para o estado, na definição de políticas públicas. Por outro lado, é interessante perceber que também nesse grupo familiar a dimensão "infanto-juvenil" apresenta um índice aceitável $(0,81)$, o que sugere um cenário em que as crianças estão em princípio mais inseridas na escola, não trabalham e a taxa de mortalidade é baixa.

Nas famílias cuja chefia é exercida por nãobrancos, a dimensão mais crítica é a disponibilidade de recursos, seguida de acesso ao conhecimento e acesso ao trabalho, repetindo o padrão encontrado de vulnerabilidade, segundo a medida usada no estudo. $\mathrm{O}$ índice encontrado nesse grupo pode refletir a situação social das pessoas não-brancas na nossa sociedade, com desigualdade de acesso à escola, de inserção no mercado de trabalho e discriminação de renda com salários mais baixos para estas pessoas. Um círculo vicioso instalado na sociedade brasileira desde a Colônia, marcado pelo contexto de uma sociedade escravagista com enraizamento no imaginário da sociedade brasileira. Políticas públicas de compensação começam a ser pensadas com o intuito de reverter tais processos gerando grande debate e controvérsia. Mas, efetivamente, esse é um grupo que apresenta vulnerabilidades expressas quando focamos nas famílias.

Por fim, é interessante ressaltar que os grupos mulheres chefes de domicílio e não-brancos che- fes de domicílio apresentam um IDF alto na dimensão desenvolvimento infanto-juvenil, o que pode ser indicativo, a ser investigado, do esforço intergeracional para transmissão de recursos e capacitação.

\section{Discussão}

Para melhor apreciação crítica dos primeiros resultados da pesquisa, devem-se resenhar, em largos traços, os termos do debate sobre sociedade de risco. Delineando os principais contornos do regime de risco, Beck 39 identifica uma grande quantidade de políticas de emprego e práticas sociais que produziram padrões gerais de insegurança. Em especial, a perspectiva analítica de sociedade de risco destaca os impactos da flexibilização e segmentação do mercado de trabalho, desencadeados ao longo das décadas de 1970 e 1980, quando se configuraram maior mobilidade e flexibilidade da força de trabalho. Nessa perspectiva, ocorreu uma série de macroprocessos que estimularam o desenvolvimento da flexibilidade, entre eles a globalização da produção, a configuração de uma nova divisão internacional do trabalho, a desregulamentação do mercado de trabalho assim como a reformulação da ordem financeira.

A tese da sociedade de risco sugere que o risco e a insegurança tornaram-se ubíquos e um aspecto constitutivo da condição moderna pairando sobre um conjunto de aspectos do mundo social, incluindo a família, as relações pessoais, a educação, o emprego e a política. Beck 39 indica uma mudança na natureza e significado dos riscos, com a passagem dos riscos predominantemente "naturais" para os chamados manufaturados, decorrentes do desenvolvimento tecnológico, o que afetou de forma explosiva os governos nacionais e os sistemas de Welfare State, com a conseqüente perda de poder das instituições para gerir em nível coletivo as conseqüências desses riscos. O resultado mais imediato é a migração da carga dos riscos da jurisdição das instituições de proteção social para a esfera individual 39,40,41.

Do que foi apresentado, emerge que as dimensões mais críticas são aquelas relativas às desigualdades de resultado, nos aspectos de disponibilidade de recursos e acesso ao mercado de trabalho, e a dimensão relativa à desigualdade de oportunidade, qual seja o acesso ao conhecimento. Os grupos mais vulneráveis são aqueles formados por famílias cujo chefe tem mais do que 65 anos de idade e por famílias cujos chefes são mulheres. Juntando-se as duas condições pode-se ter uma primeira indicação do foco de programas do tipo saúde da família: o idoso e as 
mulheres que chefiam os domicílios. No que se refere às dimensões, pode-se alegar que as três mais críticas (disponibilidade de recursos, acesso ao mercado de trabalho e acesso ao conhecimento) envolvem aspectos que fogem do escopo da ação da saúde, pois dizem respeito a questões do sistema educacional, do mercado de trabalho e da distribuição de renda, com o que se pode concordar, mas não nos impede de pensar em maneiras de como as políticas públicas de saúde, e, em particular, as de reforma do modelo assistencial, podem contribuir com efetividade para a melhoria geral das condições sociais no país.

É com base no escopo dessa discussão que devem ser interpretados os resultados do IDF apresentados neste artigo. A possibilidade de identificar grupos sociais mais vulneráveis, sobre os quais pairam condições adversas, tem - ou deveria ter - uma conseqüência imediata para uma política pública de proteção social que toma a família como seu objeto de estudo, já que aponta caminhos mais amplos de efetivação de uma política de bem-estar social centrada nos grupos mais sensíveis, os quais requerem atenção mais cuidadosa, em diversos níveis, sejam eles macro ou micro. A disponibilidade de um identificador de grupos vulneráveis de forma alguma substitui o emprego de outros instrumentos mais refinados de análise, entre os quais estão as ferramentas qualitativas, nem indica uma ordem na utilização destas ferramentas, mas, ao contrário, sugere que uma metodologia orientada pelo princípio das aproximações sucessivas talvez seja a mais indicada para tratar temas complexos.

\section{Resumo}

O artigo apresenta uma adaptação do índice de desenvolvimento da família, e detalha os resultados de sua aplicação em 21 municípios do Estado do Rio de Janeiro, Brasil no ano 2000. O estudo insere-se na pesquisa de linha de base do Projeto de Expansão e Consolidação do Saúde da Família, e foi proposto como um instrumento para acompanhamento e análise da realidade municipal no contexto de discussão de uma política pública que tem a família como eixo central. Os resultados mostram uma situação muito grave ou grave das famílias no Estado do Rio de Janeiro. As dimensões mais críticas são aquelas relativas às desigualdades de resultado, nos aspectos de disponibilidade de recursos e acesso ao mercado de trabalho; além de uma dimensão relativa à desigualdade de oportunidade, qual seja o acesso ao conhecimento. Os grupos mais vulneráveis são aqueles formados por famílias cujo chefe tem mais do que 65 anos de idade e por famílias cujos chefes são mulheres.

Iniqüidade Socia; Família; Programa Saúde da Família

\section{Colaboradores}

Todos os autores participaram igualmente na elaboração do artigo, desde a concepção, análise dos dados até a escrita propriamente dita do texto. 


\section{Referências}

1. Ministério da Saúde. Avaliação da atenção básica em saúde: caminhos da institucionalização. Brasília: Ministério da Saúde/Recife: Instituto Materno Infantil Professor Fernando Figueira; 2005.

2. Ministério da Saúde. Avaliação normativa do Programa Saúde da Família no Brasil: monitoramento da implantação e funcionamento das equipes de saúde da família: 2001-2002. Brasília: Ministério da Saúde; 2004.

3. Fundação Oswaldo Cruz. Saúde da Família: avaliação da implementação em dez grandes centros urbanos: síntese dos principais resultados. Brasília: Ministério da Saúde; 2005.

4. Ayres JRCM, França Junior I, Calazans G, Salletti H. Vulnerabilidade e prevenção em tempos de AIDS. In: Barbosa R, Parker R, organizadores. Sexualidade pelo avesso: direitos, identidades e poder. Rio de Janeiro: Editora Relume-Dumará, 1999. p. 50-71.

5. Carvalho M, Barros RP, Franco S. Índice de desenvolvimento da família. In: Acosta AR, Vitale MAF, organizadores. Família: redes, laços e políticas. São Paulo: Instituto de Estudos Especiais/Pontifícia Universidade Católica de São Paulo; 2003. p. 241-65.

6. Evans RG. Introduction. In: Evans RG, Barer ML, Marmor TR, editors. Why are some people healthy and others not? The determinants of health of the population. New York: Aldine de Gruyter; 1994. p. 3-26.

7. Dorling D, Mitchell R, Shaw M, Orford S, Smith GD. The ghost of Christmas past: health effects of poverty in London in 1896 and 1991. BMJ 2000; 321:1547-51.

8. Berkman LF, Kawachi I. A historical framework for social epidemiology. In: Berkman LF, Kawachi I, editors. Social epidemiology. New York: Oxford University Press; 2000. p. 3-12.

9. Lynch J, Kaplan G. Socioeconomic position. In: Berkman LF, Kawachi I, editors. Social epidemiology. New York: Oxford University Press; 2000. p. 13-35.

10. Barker DJ, Osmond C. Infant mortality, childhood nutrition and ischemic heart disease in England and Wales. Lancet 1986; 1:1077-81.

11. Kaplan GA. People and places: contrasting perspectives on the association between social class and health. In: Navarro V, Muntaner C, editors. Political and economic determinants of population health and well-being: controversies and developments. New York: Baywood Publishing Company; 2004. p. 495-507.

12. Burström B, Whitehead M, Lindholm C, Diderichsen $\mathrm{F}$. Inequality in the social consequences of illness: how well do people with long term illness fare in the British and Swedish labor markets? In: Navarro V, Muntaner C, editors. Political and economic determinants of population health and well-being: controversies and developments. New York: Baywood Publishing Company; 2004. p. 35-50.
13. Sassen S. The global city: New York, London, Tokyo. New Jersey: Princeton University Press; 2001.

14. Hamnett C. Unequal city: London in the global arena. London: Taylor \& Francis Group/New York: Routledge; 2003.

15. Marcuse P, Kempen RV. Globalizing cities: a new spatial order? Studies in urban and social change. Cornwall: Blackwell Publishers; 2000

16. Mollenkopf JH, Castells M. Dual city: restructuring New York: Russel Sage Foundation; 1992.

17. Silva NV, Hasenbalg CA. Pobreza e desigualdade no Brasil dos anos 80. In: Seminários estratégias liberais de refundação: dilemas contemporâneos do desenvolvimento. Rio de Janeiro: Instituto Universitário de Pesquisas do Rio de Janeiro; 1992. p. 42.

18. Ward PM. From the marginality of the 1960s to the "new poverty" of today: a LARR Research Forum. Introduction and overview: marginality then and now. Lat Am Res Rev 2004; 39:183-7.

19. Rocha S. Linhas de pobreza para as Regiões Metropolitanas na primeira metade da década de 80 . In: Anais do XVI Encontro Nacional de Economia. Belo Horizonte: Associação Nacional de Centros de Pós-Graduação em Economia; 1988. p. 81-96.

20. Rocha S, Tolosa HC. Pobreza metropolitana e políticas sociais. In: Instituto de Pesquisa Econômica Aplicada/Instituto de Pesquisas em Saúde, organizadores. Perspectivas da economia brasileira. Rio de Janeiro: Instituto de Pesquisa Econômica Aplicada; 1989. p. 403-30.

21. Rocha S. Pobreza: renda e indicadores sociais como indicadores complementares. Planej Polít Públicas 1990; (4):67-82.

22. Monteiro CA. A dimensão da pobreza, da desnutrição e da fome no Brasil. Estud Av 2003; 17:7-20.

23. Feres F, Mancebo X. El método de las necesidades básicas insatisfechas (NBI) y sus aplicaciones en América Latina. Santiago do Chile: Comisión Económica para América Latina y el Caribe; 2001. (Serie Estudios Estadísticos y Prospectivos).

24. Lustosa IGO, Figueiredo JBB. Pobreza no Brasil: métodos de análise e resultados. Pesquisa e Planejamento Econômico 1990; 20:353-80.

25. Smolka MO. Dimensões intra-urbanas da pobreza: contribuição à especificação de políticas. Rio de Janeiro: Instituto de Pesquisa e Planejamento Urbano e Regional, Universidade Federal do Rio de Janeiro; 1991.

26. Perlman JE. The myth of marginality urban poverty and politics in Rio de Janeiro. Los Angeles: California Press; 1976.

27. Valladares LP. Cem anos pensando a pobreza (urbana) no Brasil. In: Boschi RR, organizador. Corporativismo e desigualdade: a construção do espaço público no Brasil. Rio de Janeiro: Rio Fundo Editora; 1991. p. 81-112.

28. Valladares LP. Passa-se uma casa. Rio de Janeiro: Jorge Zahar Editor; 1978.

29. Valladares LP, Medeiros L. Pensando as favelas do Rio de Janeiro, 1906-2000: uma bibliografia analítica. Rio de Janeiro: Editora Relume-Dumará; 2003. 
30. Préteceille E, Valadares L. A desigualdade entre os pobres - favela, favelas. In: Henrique R, organizador. Desigualdade e pobreza no Brasil. Rio de Janeiro: Instituto de Pesquisa Econômica e Aplicada; 2000. p. 459-85.

31. Ministério da Saúde. Programa Saúde da Família: saúde dentro de casa. Brasília: Ministério da Saúde; 1994.

32. Levcovitz E, Garrido NG. Saúde da família: a procura de um modelo anunciado. Cadernos de Saúde da Família 1996; 1:3-8.

33. Ministério da Saúde. Saúde da família: uma estratégia para a reorientação do modelo assistencial. Brasília: Ministério da Saúde; 1998.

34. Ministério da Saúde. Política nacional de atenção básica. Brasília: Ministério da Saúde; 2007.

35. Pereira ATS, Campelo ACFS, Cunha FS, Noronha J, Cordeiro H, Dain S, et al. A sustentabilidade econômico-financeira no PROESF em municípios do Amapá, Maranhão, Pará e Tocantins. Ciênc Saúde Coletiva 2006; 11:607-20.
36. Instituto Brasileiro de Geografia e Estatística. Censo demográfico 2000. Rio de Janeiro: Instituto Brasileiro de Geografia e Estatística; 2000.

37. Haselbalg C, Silva NV. Origens e destinos: desigualdades sociais ao longo da vida. Rio de Janeiro: Topbooks Editora; 2003.

38. Antunes R. Riqueza e miséria do trabalho no Brasil. São Paulo: Boitempo Editorial; 2006.

39. Beck U. Risk society: towards a new modernity. London: Sage Publications; 1992.

40. Mythen G. Employment, individualization and insecurity: rethinking the risk society perspective. Sociol Rev 2005; 53:129-49.

41. Castel R. L'insécurité sociale: qu'est-ce qu'être protégé? La République des idées. Paris: Éditions du Seuil/La République des Idées; 2003.

Recebido em 22/Fev/2007

Versão final reapresentada em 23/Jan/2008

Aprovado em 31/Jan/2008 